\title{
Superparamagnetic Iron Oxide Nanoparticles: Cytotoxicity, Metabolism, and Cellular Behavior in Biomedicine Applications
}

\author{
Hao Wei ${ }^{1, *}$ \\ Yangnan $\mathrm{Hu}^{2,3, *}$ \\ Junguo Wang' \\ Xia Gao ' \\ Xiaoyun Qian (D) \\ Mingliang Tang ${ }^{2-4}$ \\ 'Department of Otolaryngology Head \\ and Neck Surgery, Affiliated Drum Tower \\ Hospital of Nanjing University Medical \\ School, Jiangsu Provincial Key Medical \\ Discipline, Nanjing, 210008, People's \\ Republic of China; ${ }^{2}$ State Key Laboratory \\ of Bioelectronics, School of Life Sciences \\ and Technology, Jiangsu Province High- \\ Tech Key Laboratory for Bio-Medical \\ Research, Southeast University, Nanjing, \\ 210096 , People's Republic of China; ${ }^{3} \mathrm{Co}$ - \\ Innovation Center of Neuroregeneration, \\ Nantong University, Nantong, 22600I, \\ People's Republic of China; ${ }^{4}$ Department \\ of Cardiovascular Surgery of the First \\ Affiliated Hospital \& Institute for \\ Cardiovascular Science, Medical College, \\ Soochow University, Suzhou, 215000, \\ People's Republic of China
}

*These authors contributed equally to this work

Correspondence: Xiaoyun Qian;

Mingliang Tang

Email qxy522@163.com;

mltang@suda.edu.cn

\begin{abstract}
Superparamagnetic iron oxide nanoparticles (SPIONs) have been widely investigated and applied in the field of biomedicine due to their excellent superparamagnetic properties and reliable traceability. However, with the optimization of core composition, shell types and transfection agents, the cytotoxicity and metabolism of different SPIONs have great differences, and the labeled cells also show different cellular behaviors. Therefore, a holistic review of the construction and application of SPIONs is desired. This review focuses the advances of SPIONs in the field of biomedicine in recent years. After summarizing the toxicity of different SPIONs, the uptake, distribution and metabolism of SPIONs in vitro were discussed. Then, the regulation of labeled-cells behavior is outlined. Furthermore, the major challenges in the optimization process of SPIONs and insights on its future developments are proposed.
\end{abstract}

Keywords: superparamagnetic iron oxide nanoparticles, stem cells, cytotoxicity, biological behavior

\section{Introduction}

Superparamagnetic nanoparticles refer to nanoscale particles with magnetic responsiveness, whose diameter is generally less than 30 nanometers. When the particle size of magnetic nanoparticles is smaller than the critical size of superparamagnetic, the particles enter the state of super magnetism. As a kind of superparamagnetic nanoparticles, superparamagnetic iron oxide nanoparticles (SPIONs) have attracted extensive attentions in the fundamental research and practical application due to their superparamagnetism under magnetic fields (MFs), ${ }^{1,2}$ biological compatibility ${ }^{3}$ and high stability. SPIONs consist of a magnetic core made of iron oxide that can be aligned with the desired area by means of an external magnet. ${ }^{4}$ During or after synthesis, SPIONs are often coated with biocompatible polymers including polyvinyl alcohol, polyethylene glycol, dextran, starch, poly(L-lysine) (PLL) ${ }^{5}$ to prevent it from polymerization, biodegradation, alteration of the structure when exposed to the body. Polymer coatings can also bind with drugs or receptors/ligands to help target-specific tissues or cells. In addition, once the MFs are removed, the magnetization of SPIONs will be extinguished. ${ }^{6,7}$ This reversible properties in magnetization allow for guidance and manipulation of the nanoparticles by exerting MFs, making it possible to manipulate cells internalize magnetic nanoparticles, and thus lead to various applications of SPIONs such us cell labeling, ${ }^{8,9}$ magnetic separation, ${ }^{10}$ microactuators $^{11,12}$ and drug delivery. ${ }^{13,14}$ 
In recent years, SPIONs have been recognized as a novel and effective tool for manipulating cell growth and behavior. Magnetic nanoparticles can be modified with various functional groups and cargos. The characteristics of magnetic nanoparticles, such as size, shape and the functional groups and cargos on the particles, together determine the interactions between nanoparticles and cells. ${ }^{15,16}$ Then the interactions determine the cellular response to the nanoparticles, which is manifested as changes in cell morphology or behavior. ${ }^{17}$ At the same time, thanks to the outstanding labeling and molecular imaging technology of SPIONs, researchers can track transplanted cells for a long time through noninvasive methods to further evaluate the biological behavior of implanted cells in the body. This method can give important information with respect to the therapeutic efficacy of the cells, as well as the safety of the therapy. The appearance of MFs may make the influence of SPIONs on cell behaviors more interesting. Recent studies have indicated that the external MFs significantly increased the migration of cells labeled with SPIONs. ${ }^{4,18}$ Due to the adjustable position and intensity of the MFs, non-invasive manipulation of cell behaviors is possible. In fact, cell therapy for lesions and injuries faces the challenge of directing engineered cells to the injury site. Therefore, the ability to manipulate cells and guide them to specific sites is of great significance in biomedicine field, and also has many potential values in cell deathrelated diseases and neurorepair therapies. ${ }^{19,20}$

However, with the optimization and development of different types of SPIONs, some consequent problems also need to be paid attention to by researchers. Although it has been successful in many applications and claimed to be safe, it is still necessary to clarify the cellular response after labeling with SPIONs. Biosafety has always been a prerequisite for biomedical applications. In recent years, several SPIONs approved for clinical use were withdrawn shortly after approval. ${ }^{21-24}$ Many studies have shown that the composition, size and surface functionalization of SPIONs are the key factors in determining their toxicity. Besides, identifying the biological distribution and metabolic pathways of SPIONs in cells or bodies will help to further guide the design and optimization of SPIONs.

In this review, we concluded the toxicological effects of SPIONs in terms of species, coating, concentration and incubation time, and further summarized the possible mechanisms of its toxicity. In addition, we discussed the uptake and metabolism pathways of SPIONs in different labeled cells, and explored temporal gradients of uptake and metabolism. Meanwhile, a lot of researches have been conducted to study the interactions between different types of cells and SPIONs. Here, we focused on cell manipulations and regulations via SPIONs and MFs. To conclude, we reviewed the literatures on the regulation of SPIONs on cell fate and behaviors, involving the influence of SPIONs on cell viability, proliferation, differentiation, migration, neurite outgrowth and orientation.

In this review, we consulted relevant articles published on prominent journals for each specific area covered in the topics in PubMed, Web of Sciences, and Wiley's Library. The search keywords included superparamagnetic nanoparticles, nanoparticle toxicity, nanoparticles for cell labeling, stem cell and neuron.

\section{Biosafety/Cytotoxicity Evaluations of SPIONs}

SPIONs can be used for biomedical applications in the fields of biology, medical diagnosis and drug delivery. Minimal cytotoxicity is a crucial requirement for any biomedical applications. Although some SPIONs have been clinically approved for medical use, their potential toxicity, especially after different modification, is still under discussion. Many researchers have investigated the cytotoxic effects of SPIONs on different types of cells. Some studies demonstrated that the viability and apoptosis of mesenchymal stem cells (MSCs) did not alter after labeling with SPIONs. ${ }^{25-28}$ Similar results by Lee et al showed that there was no influence on cultured MSCs treated with SPIONs coated with unfractionated heparin. ${ }^{29}$ What is more, some studies have analyzed the toxicity of SPIONs at the histological level. The researchers evaluated the toxicity of silica-coated SPION nanoparticles via pathological examination of organ tissue sections to assess the potential tissue damage, inflammation or pathology after administration. Histological analysis showed that the silica-coated SPIONs were injected in experimental animals, no major organs showed lesions or necrosis until 7 weeks, and no sign of tissue toxicity was found. ${ }^{30}$ With the continuous development of SPIONs research, challenges and investigations about cytotoxicity are still emerging. Therefore, we discussed some important issues that researchers should consider when designing SPIONs for special purpose. 


\section{The Types of Cores}

Due to the diversity of the cores and coatings (shells) of SPIONs, the toxicity they exhibit is also different. The core is mainly a magnetic responsive component, but some high-magnetic materials such as nickel have a certain toxicity and are easy to oxidation. ${ }^{31,32}$ It is reported that magnetite $\left(\mathrm{Fe}_{3} \mathrm{O}_{4}\right)$, maghemite $\left(\gamma-\mathrm{Fe}_{2} \mathrm{O}_{3}\right)$ and hematite $\left(\alpha-\mathrm{Fe}_{2} \mathrm{O}_{3}\right)$ are the main iron oxides, which are not only superparamagnetic, but also have good biocompatibility. Especially, $\mathrm{Fe}_{3} \mathrm{O}_{4}$ and $\gamma-\mathrm{Fe}_{2} \mathrm{O}_{3}$ are commonly employed for biomedical applications. ${ }^{31}$ In a recent study, Elkhenany et al prepared different forms of iron oxide, such as $\mathrm{Fe}_{2} \mathrm{O}_{3}, \mathrm{Fe}_{3} \mathrm{O}_{4}$ and Coxni1-x $\mathrm{Fe}_{2} \mathrm{O}_{4}$ nanoparticles to compare the security of different core and coating (shells) for adipose-derived stem cells (ASCs). They measured the percentage of apoptotic cells at the concentration of $50 \mu \mathrm{g} / \mathrm{mL}$. The results showed that the number of apoptotic cells in SPION treatment group decreased significantly compared to the control group. Interestingly, in uncoated group or ST-coated group, the proportion of apoptotic cells in ASCs labelled with $\mathrm{Fe}_{2} \mathrm{O}_{3}$ was significantly lower than in $\mathrm{Fe}_{3} \mathrm{O}_{4}$ and CoxNI1-x $\mathrm{Fe}_{2} \mathrm{O}_{4}$ nanoparticle groups. ${ }^{33}$

\section{Size of SPIONs}

The size of nanoparticles (including cores and coatings) is not only related to magnetic properties and particle internalization, but also has a certain impact on their biocompatibility, and even has a significant impact on cell behaviors. Results have shown that after systemic administration, particles larger than $200 \mathrm{~nm}$ in diameter are usually cleared by phagocytes in the spleen, while particles smaller than $10 \mathrm{~nm}$ are cleared by extravasation and renal clearance quickly. ${ }^{34}$ For systemic administration, some researchers believe that particles with a diameter range from 10 to $100 \mathrm{~nm}$ are considered to optimal. ${ }^{35}$ However, SPIONs with a particle size within this range also exhibit different toxicity, but it is difficult to perform quantitative analysis due to the presence of other factors such as coating. The main methods of measuring particle size include transmission electron microscopy (TEM) and dynamic light scattering (DLS). It is worth noting that the average size of nanoparticles measured by DLS is much larger than that measured by TEM. This difference may be due to the ability of nanoparticles to retain a certain amount of water in an aqueous solution, which makes their size larger than in the dry condition. ${ }^{36}$ The dimension of the particles determines colloidal stability, only a sufficiently small size can prevent particles from settling. ${ }^{37}$ Ultrasmall iron oxide nanoparticles $(<4 \mathrm{~nm})$ have smaller size and higher stability as compared to SPIONs $(>6 \mathrm{~nm})$. However, this does not mean that SPIONs are directly proportional to their size in cytotoxicity. Tong et al reported that SHP10nm, a SPION with a core size of $10 \mathrm{~nm}$ and coated with oleic acids and amphiphilic polymer, showed stronger cytotoxicity than SHP30nm (cell survival rate decreased by about 30\%). ${ }^{38}$ Some researchers believe that SPIONs with diameter less than $2 \mathrm{~nm}$ would destroy the structure of cell membrane and organelles, causing potential toxicity. ${ }^{35}$

\section{Coating}

Usually, the coating material can protect the magnetic core from oxidation, so that the magnetism of SPIONs can be maintained longer. With the rapid development of various surface modification technologies, many excellent coatings have been developed, making the application of SPIONs in the biomedical field has become more extensive. Some polymers can escape from the identification of the immune system and thereby extending circulation time. ${ }^{39}$ In addition, in order to avoid accelerated blood clearance, ${ }^{40}$ many efforts have been made to produce biomimetic systems suitable for drug delivery in vivo, such as cell membrane coating technology. ${ }^{41}$

However, certain coating materials could be toxic, which limits their applications in the biomedical field. Compared with other coating materials such as silica, polymers have good biocompatibility and biodegradability. For example, the use of polysaccharides (eg, dextran and chitosan), polyethylene glycol (PEG), polypyrrole (PPy), poly (D, L-lactic-co-glycolic acid) (PLGA), polylactic acid (PLA), and their copolymers as a coating can improve colloidal stability and biocompatibility. ${ }^{31}$ A study indicated that bone marrow derived MSCs could be efficiently labeled by amine-modified silica-coated SPIONs (SPIO@SiO $2_{2}-\mathrm{NH}_{2}, \mathrm{SPIO} @ \mathrm{~S}-\mathrm{N}$ ), and the labeling did not affect cell viability and osteogenesis and adipogenesis potentials. ${ }^{42}$ Yuan and colleagues reported that gold ( $\mathrm{Au}$ )coated SPIONs in MC-3T3-E1 cell line can maintain a $97 \%$ cell viability for seven consecutive days, showing the excellent biocompatibility. ${ }^{43}$ Other studies have shown that nerve growth factor (NGF) functionalized $\mathrm{Au}$ coated SPIONs (NGF-SPIO-Au) $(0.1-10 \mu \mathrm{g} / \mathrm{mL})$ also had no toxicity in PC-12 cells after 5 days of incubation. ${ }^{44}$ Gupta et al chose Pullulan as the coating material of SPIONs to prepare Pn-SPION. The results demonstrated 
that the cell survival rate of Pn-SPION at the highest concentration $(2 \mathrm{mg} / \mathrm{mL})$ can reach $92 \%$ or more compared with SPIONs (60\% loss of cell viability). ${ }^{45}$

\section{Concentration}

There are several studies have suggested that SPIONs with different physico-chemical characteristics are toxic to cells at a concentration greater than $100 \mu \mathrm{g} / \mathrm{mL} .^{46,47}$ PalaciosHernandez et al found that after exposure to ultra-small SPION (USION) coated with poly-vinylpyrrolidone (PVP)-coated, the viability of HCAECs decreased in a concentration and time-dependent manner. ${ }^{48}$ Several studies have evaluated the cytotoxicity of SPIONs with different shape, size or coatings, and found that the cytotoxicity was lower when the concentration was below 100 $\mu \mathrm{g} / \mathrm{mL}$. The researchers found that the SPIONs coated with starch or dextran were cytotoxic to PC-12 cells at high concentrations $(>100 \mu \mathrm{g} / \mathrm{mL}),{ }^{49}$ which is consistent with the report by Pisanic et al. ${ }^{50}$ At higher doses such as $500 \mu \mathrm{g} / \mathrm{mL}$, SPIONs may damage cell viability of hippocampal neural cells. ${ }^{51}$ Lee et al developed a polymeric clustered SPIO (PCS) coated with PLGA and used Cell Counting Kit 8 (CCK-8) assay to verify the toxicity of the nanoparticles. The result suggested that $80 \mu \mathrm{g} / \mathrm{mL}$ PCS did not affect cell viability within $48 \mathrm{~h}$, which leads to the conclusion that $40 \mu \mathrm{g} / \mathrm{mL}$ was the optimal therapeutic concentration. ${ }^{52}$ Egawa et al proposed a specific and fast method for labeling neural stem cells (NSCs) with SPIONs by DNA hybridization. This method was non-cytotoxic to NSCs when the concentrations of oligo[dA $]_{20}$-SPIONs ranged from 10 to $50 \mu \mathrm{g} / \mathrm{mL} .^{53}$ The results by Yuan et al suggested that the SPIO-Au core-shell nanoparticles functionalized with NGF (NGF-SPIO-Au) did not induce significant death of PC-12 cells even incubation for 5 days at the concentrations of 0.1 to $10 \mu \mathrm{g} / \mathrm{mL} .{ }^{44}$ However, it must be noted that the concentration is not the only factor to determine the toxicity of SPIONs. Certain specific coatings or stains, even at low concentrations, will exhibit cytotoxicity. Saengruengrit et al composited the monodisperse SPIONs with biocompatible PLGA and loaded BSA into the SPIO-PLGA particles (BSA/SPION-PLGA) and then evaluated the cytotoxicity in RAW264.7 cell. After incubation for $48 \mathrm{~h}$, these particles exhibited low cytotoxicity to cells at the concentration less than $300 \mu \mathrm{g} / \mathrm{mL}^{54}$ Another study demonstrated that the USPIO-Molday Ion Rhodamin B (MIRB) significantly reduced NSCs viability at the concentration of $50 \mu \mathrm{g} / \mathrm{mL}^{55}$ Combined with current findings, we conclude that the cytotoxicity of SPIONs is obviously associated with the concentration. In addition, the design of SPIONs with different surface coatings needs to be carefully selected for appropriate concentration.

\section{Cytotoxic Mechanisms}

Studies have shown that several mechanisms are involved in cytotoxicity of SPIONs such as generation of reactive oxygen species (ROS), impaired mitochondrial function, formation of apoptotic bodies, leakage of lactate dehydrogenase and DNA damage. ${ }^{46}$ It has been demonstrated that the accumulation of SPIONs may cause a temporary increase in ROS, and the oxidative stress caused by the formation of ROS is a key mechanism for the toxicity of nanomaterials. Specifically, the SPIONs release free iron under acidic $\mathrm{pH}$ environment and reducing compounds. ${ }^{46}$ Free iron then enters the cytoplasm where it interacts with hydrogen peroxide in an enzyme-catalyzed reaction to produce free radicals. ${ }^{56-58}$ Studies have suggested that after the initial ROS production induced by SPIONs treatment in cells, the cell's antioxidant defense is up-regulated, thereby effectively reduces ROS. They used glutathione and superoxide dismutase (SOD) as oxidative stress markers to evaluate the damage of SPIONs to the intracellular antioxidant system. Glutathione is the main endogenous antioxidant that protects cells from oxidative stress, which is essential for cell survival. Similarly, SOD also plays a vital role in reducing the production of harmful ROS. ${ }^{59}$ After 24 hours of incubation, all SPION-labeled NSC activities did not show a significant decrease (Figure 1A). By measuring the activity of glutathione, glutathione peroxidase and SOD, the regulation of antioxidants on oxidative stress is measured. After 4 hours of incubation, the level of glutathione in SPION-labeled NSCs decreased significantly in a concentration-dependent manner (Figure 1B). However, SOD response was not clearly dependent on the SPION dose. On the contrary, a 4-hour exposure of NSCs to SPIONs led to a dose-dependent increase in glutathione peroxidase (GPx) activity compared with the untreated cells (Figure 1C). The hyperpolarization of the mitochondrial membrane also reflects the oxidative stress response of SPION-labeled NSCs. Compared with untreated NSCs, all SPIONs, regardless of surface coating type or dosage, have increased mitochondrial membrane potential by $30 \%$ to $50 \%$ (Figure 1D). These results show that the dynamic process of the formation of ROS and the consumption of 
A

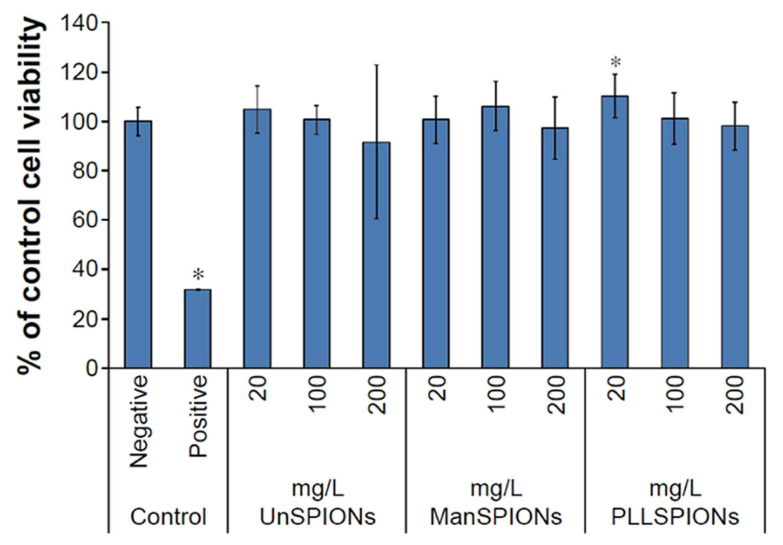

C

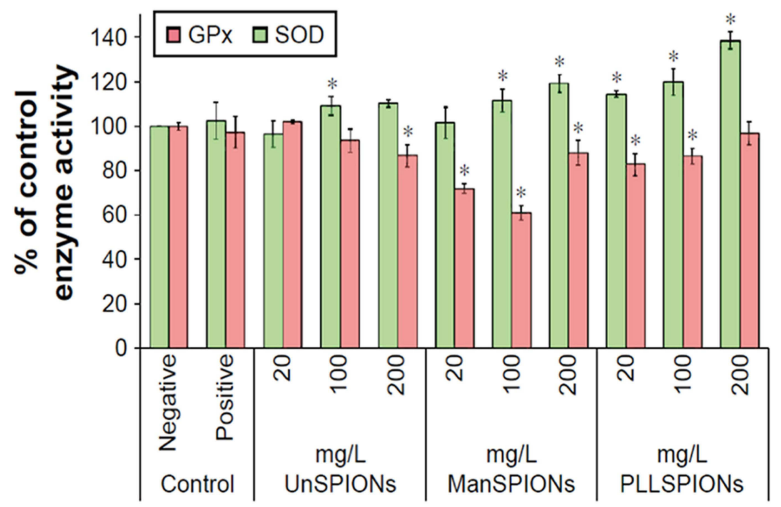

B

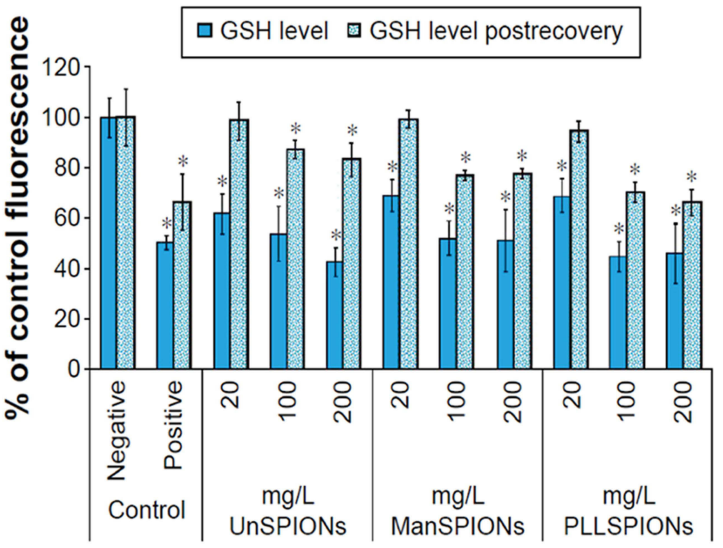

D

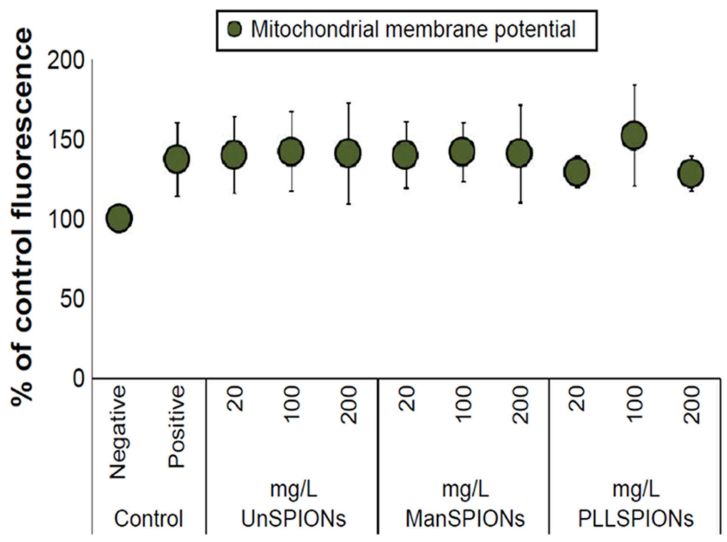

Figure I The cytotoxicity effects of SPIONs on NSCs. (A) Cell viability measured by the CCK-8 assay. (B) Total GSH content measured by monochlorobimane assay. (C) Activities of glutathione peroxidase and SOD in neural stem cells after 4 hours of exposure. (D) Mitochondrial membrane potential measured in neural stem cells after 4 hours of exposure. ${ }^{*}$ p $<0.05$. Reproduced with permission from Pongrac IM, Pavičić I, Milić M, et al. Oxidative stress response in neural stem cells exposed to different superparamagnetic iron oxide nanoparticles. Int J Nanomedicine. 2016;1 I:1701-1715. Copyright 2016, Dove Medical Press. ${ }^{59}$

glutathione and SOD constitutes the maintenance of the stability of the intracellular environment. When this balance is broken, cell mitochondrial membrane depolarization and increased ROS levels induce programmed cell death. This indicates the low or no cytotoxicity of SPIONs, which actually means that the ROS produced by the SPIONs labeled cells are maintained in a controllable range. ${ }^{59} \mathrm{He}$ et al reported that compared with SPIONs, USION had higher cytotoxicity and lactate dehydrogenase leakage in hepatic L02 cells. Through microarray and bioinformatics analysis, they found that the USION could cause stronger IL-6-related acute-phase inflammation in hepatocytes under the regulation of PERK/ATF4 pathway. ${ }^{60}$ Another possible mechanism of SPION cytotoxicity is alternations of inflammatory responses. ${ }^{61,62}$ Researchers have concluded that uncoated SPIONs can induce the production of IL-10 and inhibit TNFa. ${ }^{63}$ The study by Tong et al has shown that SHP30nm could up-regulate the IL10 mRNA level at $25 \mu \mathrm{g} / \mathrm{mL}$, suggesting a possible shift to anti-inflammatory response. However, when the concentration of SHP30nm was up to $500 \mu \mathrm{g} / \mathrm{mL}$, NOS2 and IL-12p40 were up-regulated, while IL-10 was down-regulated, indicating that the cells changed to the direction of inflammatory response. ${ }^{38}$ One possible explanation is that the large amount of SHP30nm in the monocyte-derived macrophages (MDM) cytoplasm, coupled with cytotoxicity induced by a higher dose nanoparticle, may counteract the anti-inflammatory effects of the initial low dose of SHP30nm. These results indicate the importance of dose control in biological applications of SPIONs, as carrying different 
quantities of SPIONs inside cells may lead to completely opposite results.

\section{Uptake, Distribution, and Metabolism of SPIONs}

The detailed pharmacokinetics is the key basis for the transformation of SPIONs from benchtop research to clinical settings. In fact, different applications of SPIONs also have completely different requirements for uptake, distribution and metabolism. When used as a contrast agent or a drug carrier, SPIONs often requires good uptake and metabolic efficiency. For long-term tracking in vitro or nerve and tissue repair, it may require more accurate biodistribution and stability. The characteristics of SPIONs including the composition of core and shell, size and concentration are critical for their applications. These characteristics could determine the residence time of SPIONs in the circulatory system. ${ }^{64}$ In addition, the uptake and metabolism pattern of SPIONs depend not only on their own characteristics but also the cell types. The mechanisms underlying cellular uptake, intracellular transport, and the final fate of SPIONs have not yet been clearly clarified. Here, we discuss the uptake, distribution and metabolism of SPIONs and their specific mechanisms.

\section{Uptake}

\section{Concentration}

Research by Yao et al showed that the uptake of SPIONs was concentration-dependent. SPIO@ $\mathrm{SiO}_{2}-\mathrm{NH}_{2}$ nanoparticles positively stained cells increased with the increasing concentration. They also found that for SPIONs, which were processed by different coating, the concentration threshold varied greatly. ${ }^{42}$ Naseroleslami et al's results revealed that human Amniotic mesenchymal stromal/ stem cells (hAMSCs) exhibited a dose-dependent uptake of PEG-coated SPIONs $(25-200 \mu \mathrm{g} / \mathrm{mL}){ }^{4}$ The study by Lee et al found that more than $90 \%$ of the cells internalized SPIONs after incubating at $1 \mu \mathrm{g} / \mathrm{mL}$ for $1 \mathrm{~h}$, and the highest amount of SPIONs were observed after being exposed to a concentration of $80 \mu \mathrm{g} / \mathrm{mL}$ for $24 \mathrm{~h}$. The internalization of SPIONs did not show a clear timedependent manner, but it reached maximum at $24 \mathrm{~h}$ of exposure. ${ }^{52}$ A similar result was reported that the internalization of silica-coated SPIONs increased rapidly within the first 24 hours and increased with time. ${ }^{30}$ However, for long-time exposure (48 hours), the uptake rate gradually slowed down (Figure 2A). Moreover, the uptake of nanoparticles increased with increasing concentrations. Higher concentrations of nanoparticles have a greater absorption rate than lower concentrations. Fluorescence images and Prussian blue staining of hAMSCs confirmed the uptake by intracellular nanoparticle in cytoplasmic region surrounding the nucleus (Figure 2B-F). ${ }^{30}$

\section{Sizes, Shape, Surface Charge and Coating Materials of SPIONs}

Size, shape, surface charge and coating materials of SPIONs also play critical role in cellular uptake. The shape and size of SPIONs affect cellular uptake by regulating the way in which nanoparticles bind and activate the cell membranes. The surface charge of nanoparticles affects cellular uptake by mediating surface protein adsorption and affecting the interaction between nanoparticle and cell membrane. ${ }^{65,66}$ In general, compared with SPIONs with smaller surface coating size, large SPIONs are more efficiently absorbed by monocytes and macrophages. ${ }^{67}$ However, different results have been reported. For instance, SHP10nm showed better MDM absorption efficiency than SHP30nm at $10 \mu \mathrm{g} / \mathrm{mL}$ incubation. At the concentrations of 100 and $500 \mu \mathrm{g} / \mathrm{mL}$, the absorption efficiency of SHP10nm was lower than that of SHP30nm, and the number of SHP10nm cell survival was significantly reduced. It is believed that SHP10nm exhibited higher cytotoxic effects at higher incubation doses, which further interfered with the absorption efficiency of cells. The overall results indicate that MDM may be more efficient at absorbing SHP10nm than SHP30nm. ${ }^{38}$ Although the role of SPION size in cell uptake efficiency remains unclear, researchers generally believe that SPIONs smaller than $2 \mathrm{~nm}$ in diameter are considered unsuitable for biomedical purposes. SPIONs smaller than $2 \mathrm{~nm}$ tend to produce bad influence on target cells as the increased potential to diffuse through cell membranes. ${ }^{35}$ The size of nanoparticles also affects the internalization pathway of cells. In a study by Yang, it was shown that SPIONs with a diameter of about 45-60 $\mathrm{nm}$ were internalized into macrophages through clathrinmediated pathways. ${ }^{68}$ The shape of the nanoparticles is also a crucial factor in determining cellular uptake. A recent study reported the cellular uptake behavior of USION (diameter $<4 \mathrm{~nm}$ ) and ultrathin nanowires (NWs, diameter $<4 \mathrm{~nm}$ ) on HepG2 cells. The results showed that after 72 hours of incubation, the uptake of USION was five times higher than that of NWs. ${ }^{69}$ In addition, the surface charge of SPIONs also affects their uptake and distribution 
A

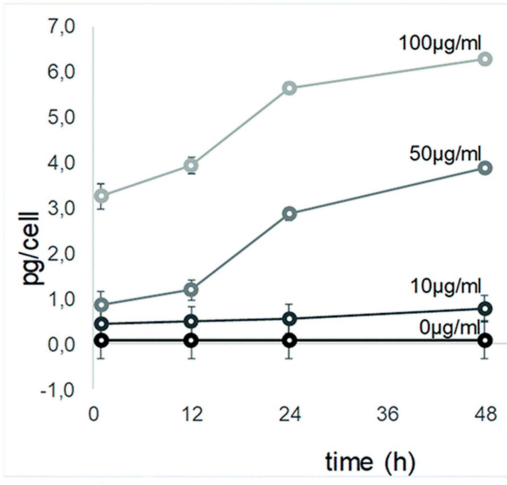

D

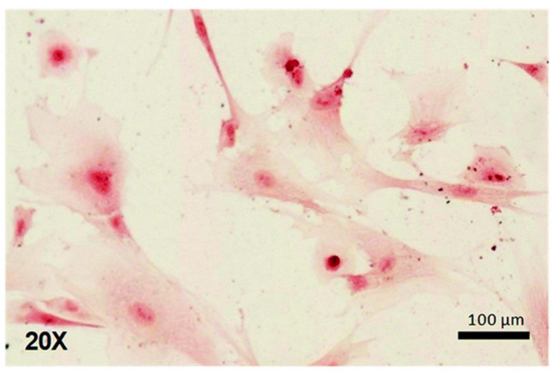

B

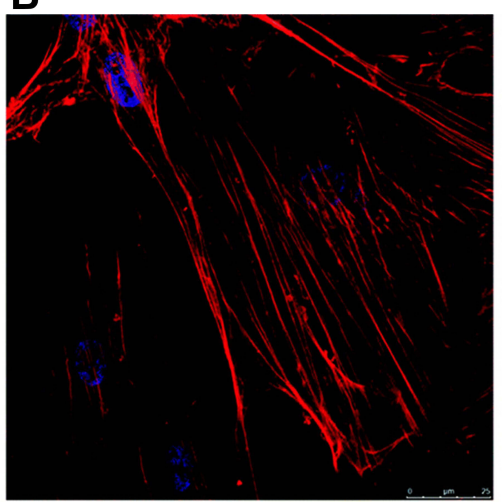

C

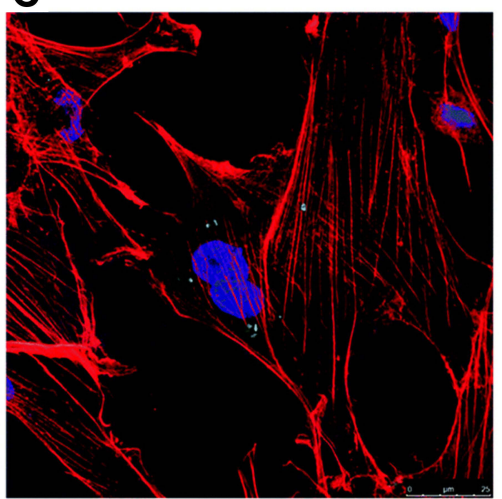

$\mathbf{E}$

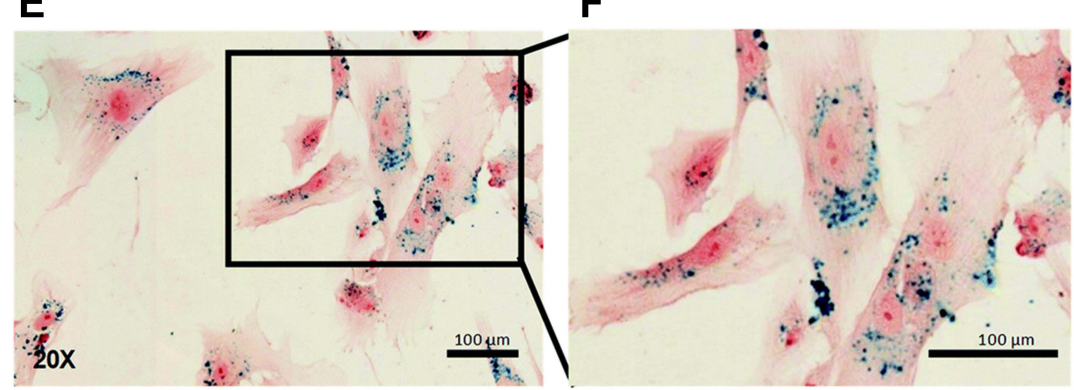

Figure 2 Cellular uptake of silica-coated SPIONs by hAMSCs. (A) The relative amount of non-heme iron inside the cells after incubating with 10,50 and $100 \mu g / m L$ of SPIONs for different time. (B) Immunofluorescence images of untreated cells. (C) Treated with $50 \mu \mathrm{g} / \mathrm{mL}$ of silica-coated SPIONs for $48 \mathrm{~h}$, nanoparticles (green), phalloidin (red) and Hoechst (blue). (D-F) Prussian blue staining of untreated cells (D), SPIONs labeled cells (E and F). Reproduced with permission from Ledda M, Fioretti D, Lolli MG, et al. Biocompatibility assessment of sub-5 $\mathrm{nm}$ silica-coated superparamagnetic iron oxide nanoparticles in human stem cells and in mice for potential application in nanomedicine. Nanoscale. 2020;12:1759-1778. Copyright 2020, Royal Society of Chemistry. ${ }^{30}$

in the body. Studies have shown that ionic SPIONs displayed better uptake efficiency than non-ionic SPIONs. ${ }^{70}$ In addition to particle size and surface charge, studies have shown that different coating materials may lead to changes in the behavior of cellular uptake. ${ }^{71}$ Sherwood et al compared the uptake of tannic acid (TA)-coated USION (TAUSION) and quinic acid (QA)-coated USION (QA-USION) in the highly aggressive primary and metastatic brain cancer cells. QA and its derivatives have been shown to interact with the P-selectin cell surface receptors. ${ }^{72-74}$ Their results indicate that QA-USION tend to selectively bind to cancer cells before being taken up by processes such as swallowing, while TA-USION are taken up non-selectively through processes such as swallowing. The result revealed that these cancer cells selectively uptaked QA-USION, which was partially mediated by $\mathrm{p}$-selectin. ${ }^{75}$

\section{Distribution}

It is important to determine the exact mechanism of the internalization of nanoparticle, which helps to more accurately locate different target sites depending on the endocytosis pathways. Whether SPIONs are used for labeling, drug delivery, or stem cell transplantation, we should clearly clarify its uptake mechanism and biodistribution. Previous reports have shown that nanoparticles with the diameter of $60 \mathrm{~nm}$ were internalized by caveolae-mediated endocytosis pathway, while the particles around $100 \mathrm{~nm}$ in size were often uptaken by receptor-mediated endocytosis. Besides, the particles around $120 \mathrm{~nm}$ usually entered the cells through clathrin-mediated endocytosis. ${ }^{76}$ The study by Lee et al reported that the $100 \mathrm{~nm}$ SPIONs crossed the cellular membrane in transport vesicles in early endosomes, late endosomes, and lysosomes. They used early endosome antigen 1 (EEA1) and late endosomes marker Rab7 to study the transport pathway of SPIONs in cells. They found that the nanoparticles were present in the early endosome after $15 \mathrm{~min}$, and some nanoparticles were observed in the late endosomes at $30 \mathrm{~min}$ and $60 \mathrm{~min}$. After incubation for $24 \mathrm{~h}$, the nanoparticles gradually gathered in the cytosol and were encapsulated in the lysosome. Interestingly, it was still co-localized with the lysosome after $60 \mathrm{~h}$ (Figure 3). ${ }^{52}$ Rojas et al used endocytosis pathway inhibitors to explore the role of astrocyte endocytosis in the accumulation of SPIONs. Their results 

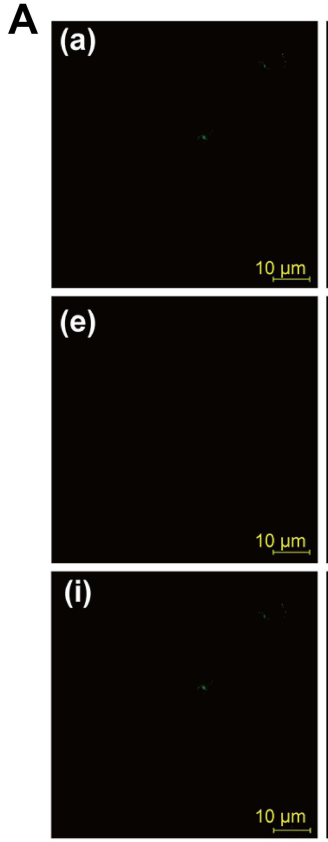
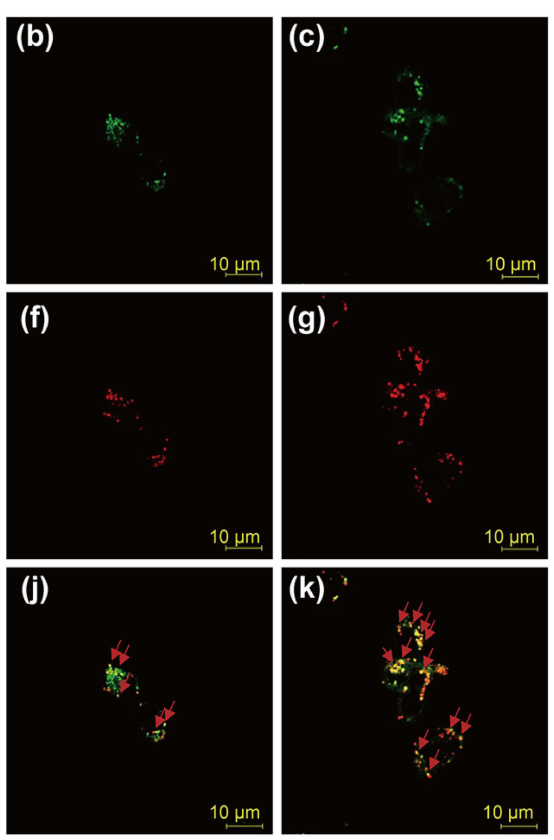
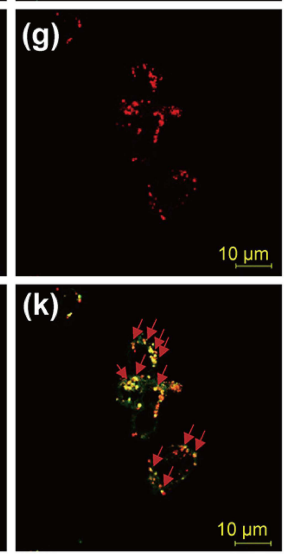
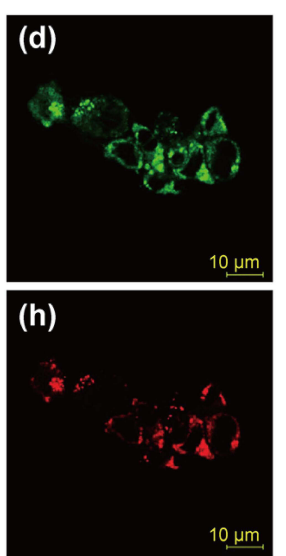

(I)

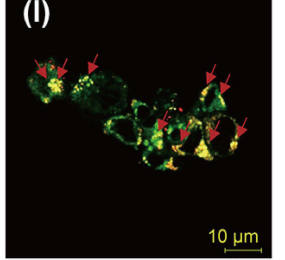

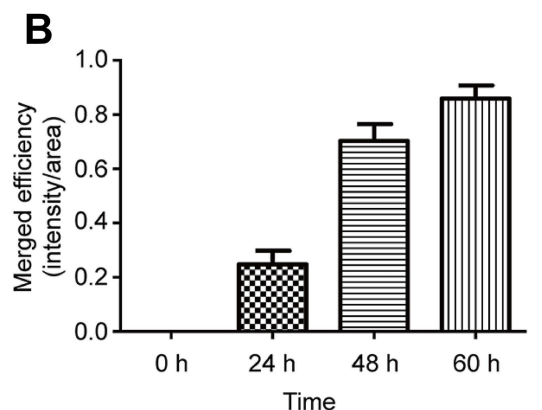

Figure 3 Fluorescence images of Cy5.5 (red)-labeled PCS localized within lysosomes (green) at different time points. (A) Control (a, e, i); PCS exposure for 24 h (b, f, j); PCS exposure for $48 \mathrm{~h}$ (c, g, k); PCS exposure for $60 \mathrm{~h}$ (d, h, l); (B) Merged fluorescence intensities PCS nanoparticle and lysosome. Reproduced with permission from Lee SH, Park DJ, Yun WS, et al. Endocytic trafficking of polymeric clustered superparamagnetic iron oxide nanoparticles in mesenchymal stem cells. $J$ Control Release. 2020;326:408-418. Copyright 2020, Elsevier. ${ }^{52}$

suggested that the presence of chlorpromazine and 5-(N-ethyl-N-isopropyl) amiloride did not change the accumulation of Fe-NP astrocyte iron, indicating clathrindependent endocytosis and large pinocytosis, respectively, did not involve in the accumulation of Fe-nanoparticles. Researchers believe that this difference may be related to the size of nanoparticles $(200-390 \mathrm{~nm})$ or coating. In addition, they observed that the internalized SPIONs were concentrated in the cytoplasm, and the MFs can significantly increase the uptake by astrocytes. The results of Prussian blue staining indicated that most SPIONs were internalized and clustered into vesicles, and cell orthogonal projections confirmed that some localized in the lysosome signal. ${ }^{77} \mathrm{Wu}$ et al's study also described the intracellular localization of particles after they were taken up by cells. They found that the nanoparticles were randomly attached to the cells without a positioning pattern, while the internalized nanoparticles were located in discrete areas of the cell, especially the area around the nucleus or the periphery of the cytoplasm. ${ }^{67}$ Wang et al investigated the distribution of SPIONs in the body when used as contrast agents, and the results suggested that $\mathrm{Fe}_{3} \mathrm{O}_{4}$-SPIONs were widely distributed in target organs and tissues such as heart, liver, spleen, lung, kidney, brain, stomach, small intestine, bone marrow, etc. The results suggested that the liver and spleen were most prominent. ${ }^{78}$ The results of another study demonstrated that nanoparticles would immediately accumulate in the kidneys for a short period of time, and then in the liver and lungs. The iron content in these areas would increase within 7 weeks. $^{30}$

Nanoparticles (NPs)-based drug delivery has some fundamental properties, such as nano size, ${ }^{79}$ high loading efficiency, ${ }^{80}$ and in vivo stability. ${ }^{81}$ Some novel nanodrugs can be released in a controlled manner by changing the composition of NP polymers. ${ }^{82}$ In addition, NPs-based vaccine carriers can activate the immune system by stimulating the inflammatory reactions of the immune system, thereby greatly enhance the resulting immune response to the encapsulated antigen. ${ }^{83}$ However, the NPs-based drug delivery system also has some limitations such as rapid clearance, low targeting efficiency and side effects. Due to the complexity of body physiology and the small size of NPs, it is difficult to develop safe and easy to track in vitro. These challenges are addressed by using an appropriate combination of different drug delivery approaches with nanomedicine vehicles.

SPIONs are widely used in nanoparticle-based delivery systems, mainly due to their superparamagnetism, biocompatibility and high stability under MFs. SPION-based delivery systems are an expanding area of research due 
to their extremely high variability in particle size selection, surface modification, packaged drug selection, and drug delivery schemes. ${ }^{84}$

\section{Metabolism and Excretion}

The terminal degradation pathway of many endocytic macromolecules is considered to be fusion with lysosomes through early and late endosomes. ${ }^{85}$ Lysosomes are essential to the metabolic process of SPIONs in cells. It is currently believed that nanoparticles dissolve under the combined action of the low $\mathrm{pH}$ environment of endosomes/lysosomes and some intracellular iron chelating substances (such as phosphates, dicarboxylic acids and nucleotides, etc). ${ }^{86,87}$ After incubating SPIONs with cells, Arbab et al performed TEM at different time points to evaluate the specific process of SPION metabolism in the cells. They observed that after incubation for $1 \mathrm{~h}$, SPIONs attached to the cell membrane and intracellular uptake was observed after incubating for $3 \mathrm{~h}$. By $72 \mathrm{~h}$, limited numbers of endosomes containing Fe-PLL complexes were found fusing with clear vacuoles. On day 5, the researchers found that the presence of nanoparticles could be observed in intracellular lysosomes. ${ }^{87}$ Some studies have pointed out that certain special coating materials can prevent water from entering the core of SPIONs. It is manifested by relatively slow degradation of SPIONs in the body, thereby increasing the half-life in the blood. Gu et al proposed three possible mechanisms for the metabolism and excretion of the internalized SPIONs in RAW264.7 cells. First, during cell mitosis, the internalized SPIONs are distributed to daughter cells. Second, the internalized SPIONs enter the lysosome and are degraded in a low $\mathrm{pH}$ environment, and free iron is released into the iron metabolism pool. Third, RAW264.7 cells may completely excrete SPIONs through exocytosis. ${ }^{88}$ Another study showed that SPIONs treatment may lead to the activation of IRE-dependent regulatory mechanisms, resulting in reduced iron uptake and increased iron export in M2 macrophages. ${ }^{77}$ The safest way to excrete SPIONs in biological systems is through the kidneys, which can minimize intracellular decomposition and reduce the production of ROS. Ledda et al studied the metabolism of SPIONs in organisms, and the results showed that the kidneys have high uptake of sub-5 SIO-Fl nanoparticles 2 hours after injection. Moreover, the iron content of the kidneys decreased significantly after one week after injection. They pointed out that the kidney is usually the main metabolic pathway for iron nanoparticles smaller than 5.5 $\mathrm{nm}$ in diameter. ${ }^{30}$ In fact, the time for SPIONs to be completely excreted in organisms is not yet clear. In a study, SPIONs-labeled mesenchymal progenitor cells (MPCs) were implanted into Achilles tendon defects of rats, and the implanted cells were tracked in vivo for longterm using quantification of bioluminescence and magnetic resonance imaging (MRI). The results showed that these cells remained and survived for at least 4 weeks after implantation. ${ }^{89}$ However, it is worth noting that in terms of long-term tracking efficacy, the time node of 4 weeks or 7 weeks is still relatively short. A relatively long duration is needed to verify the long-term effects of SPIONs and the metabolic cycle in the body.

\section{Effects on Cell Physiology}

In recent years, various cell types have been successfully labeled with SPIONs, but the impact of SPIONs on the biological properties remains elusive, such as self-renewal, proliferation, differentiation, cell cycle and apoptosis. Therefore, here we summarize the effects of different SPIONs on the proliferation, differentiation and migration of different cells, both in vivo and in vitro.

\section{Impact on Cell Proliferation}

As many experiments jointly explore the biocompatibility and proliferation, some studies on cytotoxicity will still be mentioned in this part. Various types of cells have been successfully labeled with SPIONs. The viability, morphology and behavior of cells were investigated. Specially, several studies have suggested that proliferation capacity of cells labeled with SPIONs changed compared to unlabeled cells. Researchers have attempted to use NGF functionalized Au-SPION to regulate neuronal activities under photo-stimulation. The results showed that the synergistic effect of LEDs and nanoparticles promoted the proliferation of PC-22 cells. ${ }^{90}$ Another study explored the cellular effects of Resovist (Ferucarbotran) without using a transfection agent on human mesenchymal stem cells (hMSCs). The data indicated that Ferucarbotrancan promoted the growth of hMSCs on a non-toxic basis, SRB assays further illustrated that cell proliferation displayed a dose-dependent manner. ${ }^{85,91}$ Currently, MIRB has become a new research hotspot. ${ }^{92,93} \mathrm{MIRB}$ is a kind of fluorescent SPIONs, research in human dental pulp stem cells (hDPSCs) in vitro showed that MIRB could promote cell proliferation at the concentration of $12.5-50 \mu \mathrm{g} / \mathrm{mL}$, and it exhibited toxic to hDPSCs at more than $100 \mu \mathrm{g} / \mathrm{mL}^{94}$ In another study on the survival and regeneration function of rat NSCs, the authors also used MIRB to explore the patterns. They found that 50 
$\mu \mathrm{g} / \mathrm{mL}$ MIRB significantly inhibited the survival and proliferation of cells, while the $20 \mu \mathrm{g} / \mathrm{mL}$ MIRB promoted the proliferation, ${ }^{55}$ which indicated that the concentration is also an important factor affecting cell behaviors and fate. In the studies by Pongrac et al, NSCs treated with PLL- $\gamma-\mathrm{Fe}_{2} \mathrm{O}_{3}$ performed well in viability and proliferation. ${ }^{95}$ In vivo experiments also showed that the implanted cells co-labeled with SPIO nanoparticles not only survived, but also proliferated in vivo, with the cells surviving for at least four weeks after implantation. ${ }^{89}$

However, some studies indicated that the SPIONs had no obvious effect on cell proliferation or even inhibited cell proliferation. For example, there was no change in cell proliferation of human neural progenitor cells. ${ }^{96}$ Wang et al reported the effect of PLL-modified SPIONs on the viability and proliferation capacity of glioblastoma cancer stem cells in vitro, and the results did not show significant differences. ${ }^{97}$ A study demonstrated that labeling adipose-derived stem cells with $\mathrm{Fe}_{2} \mathrm{O}_{3}, \mathrm{ST}-\mathrm{Fe}_{2} \mathrm{O}_{3}, \mathrm{Fe}_{3} \mathrm{O}_{4}$ or ST-Fe $\mathrm{O}_{3}$ did not affect their proliferation capacity. $\mathrm{CoxNi}-\mathrm{xFe}_{2} \mathrm{O}_{4}$ is considered to have good magnetic properties, but the results show that both $\mathrm{CoxNi1}-\mathrm{xFe}_{2} \mathrm{O}_{4}$ and its ST-coated form caused a significant decrease in the proliferation rate. ${ }^{33}$ The authors believe that this result may be related to the cytotoxic effect of nickel. ${ }^{33}$ Ren et al demonstrated that cynomolgus MSCs (cMSCs) proliferation was reduced in passage 5 and passage 6 generations after $20 \mu \mathrm{g} / \mathrm{mL}$ MIRB was used to label cMSCs. ${ }^{98}$ The mechanisms involved in these differences in cell proliferation after labelling with different SPIONs are still not clear at present. Some studies consider the differences in toxicity results from different types and coating. ${ }^{33,98}$

\section{Impact on Stem Cell Differentiation}

SPIONs have been used in the field of stem cell transplantation and regeneration due to their good stem cell labeling capacity and targeted transport ability. MRI can determine the behavior of SPION-labeled stem cells in vivo, especially their potential to migrate and transform into the desired specific cells within the target structure. The acquisition of this information also solves the problem of lack of understanding of the behavior after stem cell transplantation in the past. Some studies have shown that SPIONs can maintain the stemness of stem cells without affecting the differentiation ability of stem cells. ${ }^{99-101}$ In a research by Egawa et al, the oligo[dA]20-SPION had no effect on cell differentiation in vitro and in vivo. ${ }^{53}$ Lee et al's study also indicated that MSCs did not lose their inherent differentiation characteristics after treating with polymeric clustered SPIO. ${ }^{52}$ Egawa et al used DNA hybridization to label NSCs with SPIONs and transplant in vivo. One month post-transplantation, SPION-labeled and no-labeled transplanted cells $\left(\mathrm{GFP}^{+}\right)$were confirmed to survive and grow well in the host tissue. Immunohistology (Figure 4) showed that there were no GFP and nestin double-positive cells $\left(\mathrm{GFP} /\right.$ nestin $\left.^{+/+}\right)($Figure $4 \mathrm{~A}$ and E), indicating that all transplanted cells differentiated in vivo. Most of the transplanted cells differentiated into glial cell line (Figure 4D and $\mathrm{H}$ ). It was shown that there was no obvious neuronal differentiation (Figure 4B, C, F and G). The results of the study showed that the transplanted cells labeled with SPIONs differentiated normally in vivo and mainly differentiated into glial cells. ${ }^{53}$ Eamegdool et al also analyzed the cell phenotype of SPION-labeled human fetal neural precursor cells (hNPCs) by immunofluorescence, and quantified the proportion of astrocytes, neurons, and oligodendrocytes. The results prove that hNPCs labeled with SPIONs retain pluripotency and can differentiate into various major neuronal cell types. ${ }^{102}$

In addition, some studies have found that certain functionalized SPIONs can promote stem cell differentiation. Studies have shown that SPION-labeled NSCs can survive well and differentiate into neurons and glial cells after transplantation into the central nervous system of rodents and monkeys. ${ }^{100,101,103}$ The results by Yuan et al showed that NGF-SPIONs-Au can promote the growth and differentiation of PC-12 under external MFs, and dynamic MFs was better than their static counterparts. They also found that the differentiation ratio and the neurite length elongation were increased significantly. ${ }^{90}$ These seemingly contradictory results may be related to the difference in core composition, core shell, size, concentration of nanoparticles and the addition of different transfection agents.

\section{Impact on Cell Migration}

Cell migration is essential for tissue regeneration and the development of the central nervous system. Impaired migration will slow down tissue regeneration ${ }^{104}$ and even cause developmental abnormalities in the central system. ${ }^{105,106}$ Extensive researches in bioengineering have been focused on reducing the long recovery time. We therefore discuss the effects of SPIONs on cell migration and possible mechanisms. In Kurniawan et al's study, the scratch assay was used to assess the migration capacity of hematopoietic stem cells. It was observed that the migration was significantly and dosedependently inhibited by an increasing concentration of FGF2-SPIONs. ${ }^{107} \mathrm{~A}$ similar result was obtained by 


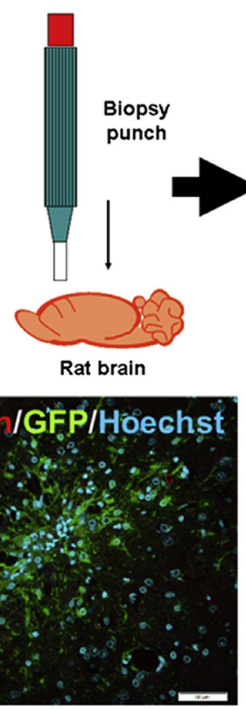

Isolate the transplantation region

Tissue sectioning in the horizontal plane

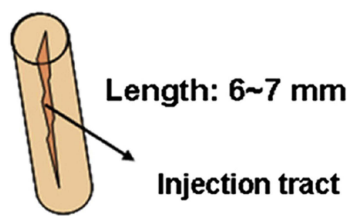

$3 \mathrm{~mm} \varnothing$
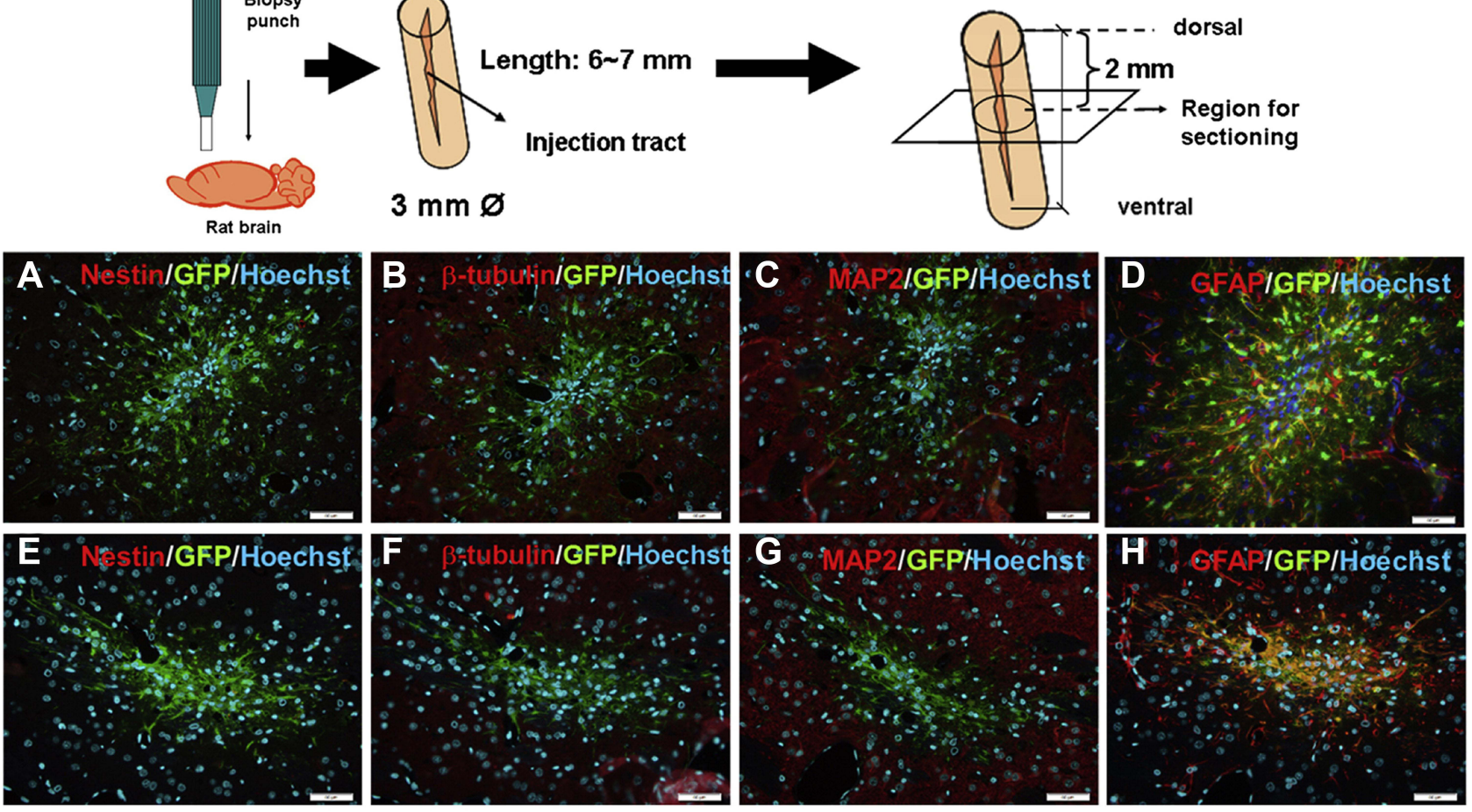

Figure 4 Immunohistology of grafts one-month post-transplantation. (A-D) SPIO-labeled NSCs with nestin (A), $\beta$-tubulin (B), MAP2 (C), GFAP (D). (E-H) SPIO-labeled NSCs with nestin (E), $\beta$-tubulin (F), MAP2 (G), GFAP (H) staining. Scale Bar=50 mm. Reproduced with permission from Egawa EY, Kitamura N, Nakai R, et al. A DNA hybridization system for labeling of neural stem cells with SPIO nanoparticles for MRI monitoring post-transplantation. Biomaterials. 20I5;54:I58-167. Copyright 20I5, Elsevier. ${ }^{53}$

Elkhenany et al. ${ }^{33}$ Embedding or coupling drugs into SPIONs can effectively solve the problems of poor solubility, limited stability, fast metabolism and adverse side effects. Therefore, some drug-loaded SPIONs are used in the field of tumor treatment. In order to verify the influence of SPIONs on tumor cell migration, 3D solid tumor in vitro is used as a more accurate evaluation standard model. The results of migration assays on E297 spheroids treated with $5 \mathrm{mg} / \mathrm{mL}$ $\mathrm{SiO}_{2}$-SPIONs showed that these particles were very effective in preventing the migration of cells from the sphere itself, which indicates that the nanoparticles can limit the spread of tumor cells, thereby restricting the invasion ability of tumors. ${ }^{67}$ Mardhian et al synthesized a nanoparticle system by chemically conjugating RLX, an endogenous hormone, to SPIONs for the treatment of pancreatic cancer. The results of collagen gel assay showed that RLX-SPIONs significantly inhibited the contraction induced by TGF $\beta$ (Figure 5A). Scratch assays also showed that RLX-SPIONs significantly inhibited the migration of human pancreatic stellate cells (hPSC) (Figure 5B). In vitro tumor models also confirmed that RLX-SPIONs can significantly inhibit tumor growth. ${ }^{108}$
Some studies have tried to explore the mechanism of SPIONs on cell migration. Studies have suggested that PEI-SPIONs restrict the migration of HUVEC cells by changing the activity of the actin cytoskeleton. ${ }^{109}$ Soenen et al believed that cellular actin cytoskeleton and microtubule networks were destroyed, resulting in loss of focal adhesion and decreased migration ability, when the concentration of SPIONs in cells was too high. ${ }^{110}$ It has also been demonstrated that cell migration could be related to the energy content of cells, and required a higher intracellular ATP level. ${ }^{111}$ Elkhenany et al found that the migration ability of ASCs labeled with uncoated SPIONs was significantly inhibited. Interestingly, starch coating with nanoparticles reversed this inhibition on migration. Higher migration capacity was reported after treating cells with $\mathrm{ST}-\mathrm{Fe}_{2} \mathrm{O}_{3}$ and $\mathrm{ST}-\mathrm{Fe}_{3} \mathrm{O}_{4} \cdot{ }^{33}$ This result can be attributed to higher energy needs of cells, either to support migration activity itself or to resist the cytotoxic effects caused by SPIONs.

It is worth noting that when MFs are added, the migration effects of cells labeled SPIONs show the opposite 

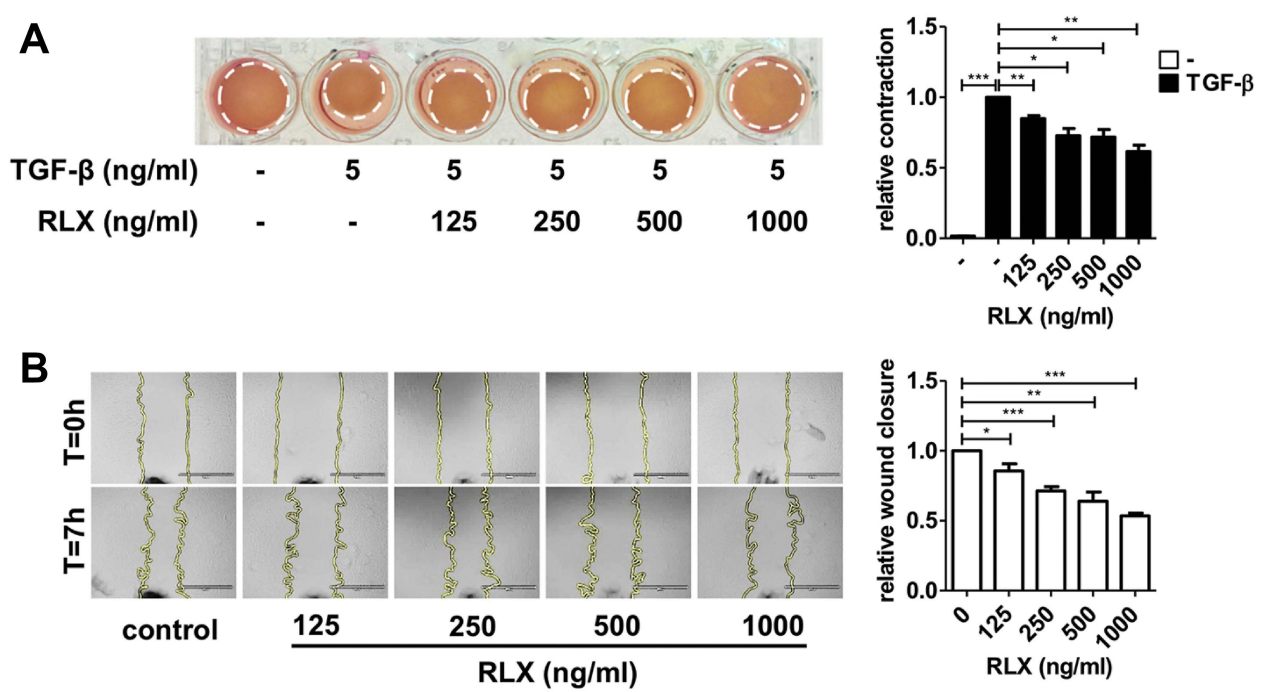

Figure 5 Effect of RLX-SPION on hPSCs contractility and migration. (A) Representative images and quantification. (B) Representative microscopic images and quantification showing. Statistical differences are $*_{p}<0.05, * *_{p}<0.01$, $*_{*}^{*} p<0.00 \mathrm{I}$. Reproduced with permission from Mardhian DF, Storm G, Bansal R, et al. Nano-targeted relaxin impairs fibrosis and tumor growth in pancreatic cancer and improves the efficacy of gemcitabine in vivo. J Control Release. 2018;290:I-10. Copyright 2018, Elsevier. ${ }^{108}$

result. The inhibition of migration is often reversed by MFs. The magnetic property of SPIONs is determined by size. In addition, there are many factors that specifically affect biological properties of labeled cells, such as the chemical composition of both core and shell, hydrophobicity/hydrophilicity and so on. ${ }^{64,112}$ Jasmin et al labeled endothelial progenitor cells (EPCs) with silica-coated SPIONs, and applied external MFs to guide EPCs labeled with silica-coated SPIONs. They found that external MFs would significantly induce silica-coated SPION-labeled EPCs to migrate to ischemic areas for homing. ${ }^{113}$ Elkhenany et al labeled cardiosphere-derived cells with SPIONs. Interestingly, the cells were recruited by the magnet to the periphery of the ischemic area under the magnetic targeting force. The migration of SPION-labeled cells is reduced after transplantation, which will affect its therapeutic effect. When the external MFs is removed, its influence on the migration of labeled cells will disappear immediately. ${ }^{33}$ This controlled change provides more possibilities for the application of SPIONs in biomedicine.

\section{Conclusions and Perspectives}

In recent years, the application of SPIONs in the field of biomedicine has received extensive attention. In this review, we summarized the latest development of SPIONs in the field of biology. By analyzing the differences in toxicity of different composition, size, and surface functionalization of SPIONs, assessing their biological application value and potential health effects, and identifying the physical and chemical properties related to the toxicity. It is expected to provide certain reference value for researchers to design more secure SPIONs. All these SPIONs with different properties will cause specific cytotoxicity when interacting with the different physiological system. There is still no reliable or uniform standard to predict the long-term effects of SPIONs in organisms. In view of what has been described above, we believe that the coating and surface modification of SPIONs are the biggest variables that affect cytotoxicity. While the development of surface modification methods has greatly developed the application of SPIONS, it has brought huge challenges to the biosafety of SPIONs. Then, sizes, surface charge and coating are the key factors affecting the uptake and distribution process of the SPIONs. After internalizing SPIONs, the proliferation, differentiation and migration of cells are often affected, which have been specifically discussed in the previous section.

By exploring the cytotoxicity, proliferation, differentiation and migration capabilities of SPIONs on different types of cells, as well as the mechanisms of their uptake, distribution and metabolism in cells and even in vivo, this review provides more possibilities and theoretical foundations for SPIONs in innovative nanomedicine applications. What is certain is that SPIONs have the characteristics of an excellent biomedical carrier, while having long-term in vitro tracking effects. These excellent biological performances make SPIONs 
show great potential in the field of biomedicine, especially in the field of neural engineering. At the same time, we believe that the current clinical application of SPIONs still faces many challenges.

Some researchers believe that the complete vitro evaluation system of SPION cytotoxicity should be analyzed from different aspects, such as optical detection, ROS and/ or inflammatory factor levels, and enzyme activity, etc. The specific evaluation mechanism also needs to be combined with the metabolic pathway and time of SPIONs in cells/in vivo, and the long-term effects of SPIONs on cell function. At present, most of the overall effects of SPIONs on the biological effect of labeled cells have not been well understood and determined. Significantly, the most of researches is still based on in vitro experiments, which needs to be further confirmed by more animal experiments and clinical trials. In future work, researchers should establish a well-defined system for the in vivo application of SPIONs. It should include generally applicable biological assessments of any type of nanoparticles, standardization of SPION characterization, and selection of test cell lines that are closely related to the intended application of SPIONs in vivo. In addition, for some reproducible nanomedicine designs aimed at solving clinical problems, researchers should conduct extensive interdisciplinary exchanges.

\section{Abbreviations}

SPIONs, superparamagnetic iron oxide nanoparticles; PLL, poly(L-lysine); MFs, magnetic fields; MSCs, mesenchymal stem cells; ASCs, adipose-derived stem cells; TEM, transmission electron microscopy; DLS, dynamic light scattering; PEG, PPy, polyethylene glycol; polypyrrole; PLGA, poly (D, L-lactic-co-glycolic acid); PLA, polylactic acid; USION, ultra-small SPION; PVP, poly-vinylpyrrolidone; PCS, polymeric clustered SPIO; CCK-8, cell counting kit 8; NSCs, neural stem cells; MIRB, molday ion rhodamin B; ROS, reactive oxygen species; SOD, superoxide dismutase; GPx, glutathione peroxidase; MDM, monocyte-derived macrophages; hAMSCs, human amniotic mesenchymal stromal/stem cells; TA, tannic acid; QA, quinic acid; EEA1, early endosome antigen 1; MPCs, mesenchymal progenitor cells; MRI, magnetic resonance imaging; EPCs, endothelial progenitor cells; hMSCs, human mesenchymal stem cells; hDPSCs, human dental pulp stem cells; cMSCs, cynomolgus MSCs; GFP, green fluorescent protein; hNPCs, human fetal neural precursor cells.

\section{Funding}

This work is supported by grants from the Major State Basic Research Development Program of China (2017YFA0104303), the National Natural Science Foundation of China (No. 81970883, 81970885), the Six talent peaks project in Jiangsu Province (Grant Nos. YY073), and the Project of Invigorating Health Care through Science, Technology and Education.

\section{Disclosure}

The authors declare non-financial competing interests in this work.

\section{References}

1. Andreu I, Natividad E, Solozabal L, et al. Nano-objects for addressing the control of nanoparticle arrangement and performance in magnetic hyperthermia. ACS Nano. 2015;9:1408-1419. doi:10.1021/nn505781f

2. Mashhadi Malekzadeh A, Ramazani A, Tabatabaei Rezaei SJ, et al. Design and construction of multifunctional hyperbranched polymers coated magnetite nanoparticles for both targeting magnetic resonance imaging and cancer therapy. $J$ Colloid Interface Sci. 2017;490:64-73. doi:10.1016/j.jcis.2016.11.014

3. Nguyen D, Pham BT, Huynh Vet al. Monodispersed polymer encapsulated superparamagnetic iron oxide nanoparticles for cell labeling. Polymer. 2016;106:238-248.

4. Naseroleslami M, Aboutaleb N, Parivar K. The effects of superparamagnetic iron oxide nanoparticles-labeled mesenchymal stem cells in the presence of a magnetic field on attenuation of injury after heart failure. Drug Deliv Transl Res. 2018;8:1214-1225. doi:10.1007/s13346-018-0567-8

5. Jarrett BR, Frendo M, Vogan J, et al. Size-controlled synthesis of dextran sulfate coated iron oxide nanoparticles for magnetic resonance imaging. Nanotechnology. 2007;18:035603. doi:10.1088/ 0957-4484/18/3/035603

6. Laurent S, Forge D, Port M, et al. Magnetic iron oxide nanoparticles: synthesis, stabilization, vectorization, physicochemical characterizations, and biological applications. Chem Rev. 2008;108:2064-2110.

7. Wu L, Mendoza-Garcia A, Li Q, et al. Organic phase syntheses of magnetic nanoparticles and their applications. Chem Rev. 2016;116:10473-10512. doi:10.1021/acs.chemrev.5b00687

8. Ramaswamy S, Greco JB, Uluer MC, et al. Magnetic resonance imaging of chondrocytes labeled with superparamagnetic iron oxide nanoparticles in tissue-engineered cartilage. Tissue Eng Part A. 2009;15(12):3899-3910. doi:10.1089/ten. tea.2008.0677

9. Saldanha KJ, Doan RP, Ainslie KM, et al. Micrometer-sized iron oxide particle labeling of mesenchymal stem cells for magnetic resonance imaging-based monitoring of cartilage tissue engineering. Magn Reson Imaging. 2011;29:40-49. doi:10.1016/ j.mri.2010.07.015

10. Xu H, Aguilar ZP, Yang L, et al. Antibody conjugated magnetic iron oxide nanoparticles for cancer cell separation in fresh whole blood. Biomaterials. 2011;32:9758-9765. doi:10.1016/j. biomaterials.2011.08.076

11. Chen XZ, Hoop M, Mushtaq F, et al. Recent developments in magnetically driven micro- and nanorobots. Appl Mater Today. 2017;9:37-48. doi:10.1016/j.apmt.2017.04.006 
12. Kim J, Chung SE, Choi SE, et al. Programming magnetic anisotropy in polymeric microactuators. Nat Mater. 2011;10:747-752. doi:10.1038/nmat3090

13. Ulbrich K, Holá K, Šubr V, et al. Targeted drug delivery with polymers and magnetic nanoparticles: covalent and noncovalent approaches, release control, and clinical studies. Chem Rev. 2016;116:5338-5431. doi:10.1021/acs.chemrev.5b00589

14. Zhu L, Wang D, Wei X, et al. Multifunctional pH-sensitive superparamagnetic iron-oxide nanocomposites for targeted drug delivery and MR imaging. J Control Release. 2013;169:228-238. doi:10.1016/j.jconrel.2013.02.015

15. Singh AV, Maharjan RS, Kanase A, et al. Machine-learning-based approach to decode the influence of nanomaterial properties on their interaction with cells. ACS Appl Mater Interfaces. 2021;13:1943-1955. doi:10.1021/acsami.0c18470

16. Singh AV, Ansari MHD, Rosenkranz D, et al. Artificial intelligence and machine learning in computational nanotoxicology: unlocking and empowering nanomedicine. Adv Healthc Mater. 2020;9:e1901862. doi:10.1002/adhm.201901862

17. Polak P, Shefi O. Nanometric agents in the service of neuroscience: manipulation of neuronal growth and activity using nanoparticles. Nanomedicine. 2015;11:1467-1479. doi:10.1016/j. nano.2015.03.005

18. Li Q, Tang G, Xue S, et al. Silica-coated superparamagnetic iron oxide nanoparticles targeting of EPCs in ischemic brain injury. Biomaterials. 2013;34:4982-4992. doi:10.1016/j. biomaterials.2013.03.030

19. Cores J, Caranasos TG, Cheng K. Magnetically targeted stem cell delivery for regenerative medicine. $J$ Funct Biomater. 2015;6:526-546. doi:10.3390/jfb6030526

20. Singh AV, Chandrasekar V, Janapareddy P, et al. Emerging application of nanorobotics and artificial intelligence to cross the BBB: advances in design, controlled maneuvering, and targeting of the barriers. ACS Chem Neurosci. 2021;12:1835-1853. doi:10.1021/ acschemneuro.1c00087

21. Küstermann E, Himmelreich U, Kandal K, et al. Efficient stem cell labeling for MRI studies. Contrast Media Mol Imaging. 2008;3:27-37. doi:10.1002/cmmi.229

22. Novotna B, Jendelova P, Kapcalova M, et al. Oxidative damage to biological macromolecules in human bone marrow mesenchymal stromal cells labeled with various types of iron oxide nanoparticles. Toxicol Lett. 2012;210:53-63. doi:10.1016/j. toxlet.2012.01.008

23. Chen J, Rogers SC, Kavdia M. Analysis of kinetics of dihydroethidium fluorescence with superoxide using xanthine oxidase and hypoxanthine assay. Ann Biomed Eng. 2013;41:327-337. doi:10.1007/s10439-012-0653-x

24. Benetti F, Bregoli L, Olivato I, et al. Effects of metal(loid)-based nanomaterials on essential element homeostasis: the central role of nanometallomics for nanotoxicology. Metallomics. 2014;6:729-747. doi:10.1039/c3mt00167a

25. Schafer R, Kehlbach R, Muller M, et al. Labeling of human mesenchymal stromal cells with superparamagnetic iron oxide leads to a decrease in migration capacity and colony formation ability. Cytotherapy. 2009;11:68-78. doi:10.1080/ 14653240802666043

26. Zhang R, Li J, Li J, et al. Efficient In vitro labeling rabbit bone marrow-derived mesenchymal stem cells with SPIO and differentiating into neural-like cells. Mol Cells. 2014;37:650-655. doi:10.14348/molcells.2014.0010

27. Xu L, Yuan S, Chen W, et al. Transplantation and tracking of the human umbilical cord mesenchymal stem cell labeled with superparamagnetic iron oxide in deaf pigs. Anat Rec. 2020;303:494-505. doi:10.1002/ar.24346
28. Singh AV, Dad ansari MH, Dayan CB, et al. Multifunctional magnetic hairbot for untethered osteogenesis, ultrasound contrast imaging and drug delivery. Biomaterials. 2019;219:119394. doi:10.1016/j.biomaterials.2019.119394

29. Lee JH, Jung MJ, Hwang YH, et al. Heparin-coated superparamagnetic iron oxide for in vivo MR imaging of human MSCs. Biomaterials. 2012;33:4861-4871. doi:10.1016/j. biomaterials.2012.03.035

30. Ledda M, Fioretti D, Lolli MG, et al. Biocompatibility assessment of sub-5 nm silica-coated superparamagnetic iron oxide nanoparticles in human stem cells and in mice for potential application in nanomedicine. Nanoscale. 2020;12:1759-1778. doi:10.1039/ C9NR09683C

31. Mahmoudi M, Sant S, Wang B, et al. Superparamagnetic iron oxide nanoparticles (SPIONs): development, surface modification and applications in chemotherapy. Adv Drug Deliv Rev. 2011;63:24-46.

32. Tartaj P, Serna CJ. Synthesis of monodisperse superparamagnetic Fe/silica nanospherical composites. $J$ Am Chem Soc. 2003;125:15754-15755. doi:10.1021/ja0380594

33. Elkhenany H, Abd Elkodous M, Ghoneim NI, et al. Comparison of different uncoated and starch-coated superparamagnetic iron oxide nanoparticles: implications for stem cell tracking. Int $J$ Biol Macromol. 2020;143:763-774. doi:10.1016/j.ijbiomac.2019.10.031

34. Gupta AK, Wells S. Surface-modified superparamagnetic nanoparticles for drug delivery: preparation, characterization, and cytotoxicity studies. IEEE Trans Nanobioscience. 2004;3:66-73. doi:10.1109/TNB.2003.820277

35. Wahajuddin AS. Superparamagnetic iron oxide nanoparticles: magnetic nanoplatforms as drug carriers. Int $J$ Nanomedicine. 2012;7:3445-3471. doi:10.2147/IJN.S30320

36. Hao $\mathrm{X}, \mathrm{Xu} \mathrm{B}, \mathrm{Chen} \mathrm{H}$, et al. Stem cell-mediated delivery of nanogels loaded with ultrasmall iron oxide nanoparticles for enhanced tumor MR imaging. Nanoscale. 2019;11:4904-4910. doi:10.1039/C8NR10490E

37. Kubinová S, Syková E. Nanotechnology for treatment of stroke and spinal cord injury. Nanomedicine. 2010;5:99-108. doi: $10.2217 / \mathrm{nnm} .09 .93$

38. Tong HI, Kang W, Shi Y, et al. Physiological function and inflamed-brain migration of mouse monocyte-derived macrophages following cellular uptake of superparamagnetic iron oxide nanoparticles-Implication of macrophage-based drug delivery into the central nervous system. Int $J$ Pharm. 2016;505:271-282. doi:10.1016/j.ijpharm.2016.03.028

39. Wang JL, Du XJ, Yang JX, et al. The effect of surface poly (ethylene glycol) length on in vivo drug delivery behaviors of polymeric nanoparticles. Biomaterials. 2018;182:104-113. doi:10.1016/j.biomaterials.2018.08.022

40. Shiraishi K, Hamano M, Ma H, et al. Hydrophobic blocks of PEG-conjugates play a significant role in the accelerated blood clearance (ABC) phenomenon. $J$ Control Release. 2013;165:183-190. doi:10.1016/j.jconrel.2012.11.016

41. Liu Y, Luo J, Chen X, et al. Cell membrane coating technology: a promising strategy for biomedical applications. Nanomicro Lett. 2019;11:100.

42. Yao D, Liu NN, Mo BW. Assessment of proliferation, migration and differentiation potentials of bone marrow mesenchymal stem cells labeling with silica-coated and amine-modified superparamagnetic iron oxide nanoparticles. Cytotechnology. 2020;72:513-525. doi:10.1007/s10616-020-00397-5

43. Yuan M, Wang Y, Qin YX. SPIO-Au core-shell nanoparticles for promoting osteogenic differentiation of MC3T3-E1 cells: concentration-dependence study. $J$ Biomed Mater Res A. 2017;105:3350-3359. doi:10.1002/jbm.a.36200 
44. Yuan M, Wang Y, Qin YX. Promoting neuroregeneration by applying dynamic magnetic fields to a novel nanomedicine: superparamagnetic iron oxide (SPIO)-gold nanoparticles bounded with nerve growth factor (NGF). Nanomedicine. 2018;14:1337-1347. doi:10.1016/j.nano.2018.03.004

45. Gupta AK, Gupta M. Cytotoxicity suppression and cellular uptake enhancement of surface modified magnetic nanoparticles. Biomaterials. 2005;26:1565-1573. doi:10.1016/j.biomateria 1s.2004.05.022

46. Singh N, Jenkins GJ, Asadi R, et al. Potential toxicity of superparamagnetic iron oxide nanoparticles (SPION). Nano Rev. 2010;1:5358.

47. Yildirimer L, Thanh NT, Loizidou M, et al. Toxicology and clinical potential of nanoparticles. Nano Today. 2011;6:585-607. doi:10.1016/j.nantod.2011.10.001

48. Palacios-Hernandez T, Diaz-Diestra DM, Nguyen AK, et al. Cytotoxicity, cellular uptake and apoptotic responses in human coronary artery endothelial cells exposed to ultrasmall superparamagnetic iron oxide nanoparticles. J Appl Toxicol. 2020;40 (7):918-930. doi:10.1002/jat.3953

49. Marcus M, Karni M, Baranes K, et al. Iron oxide nanoparticles for neuronal cell applications: uptake study and magnetic manipulations. J Nanobiotechnology. 2016;14:37. doi:10.1186/ s12951-016-0190-0

50. Pisanic TR, Blackwell JD, Shubayev VI, et al. Nanotoxicity of iron oxide nanoparticle internalization in growing neurons. Biomaterials. 2007;28:2572-2581. doi:10.1016/j.biomaterials.2007.01.043

51. Khalid MK, Asad M, Henrich-Noack P, et al. Evaluation of toxicity and neural uptake in vitro and in vivo of superparamagnetic iron oxide nanoparticles. Int J Mol Sci. 2018;19:2613.

52. Lee SH, Park DJ, Yun WS, et al. Endocytic trafficking of polymeric clustered superparamagnetic iron oxide nanoparticles in mesenchymal stem cells. J Control Release. 2020;326:408-418. doi:10.1016/j.jconrel.2020.07.032

53. Egawa EY, Kitamura N, Nakai R, et al. A DNA hybridization system for labeling of neural stem cells with SPIO nanoparticles for MRI monitoring post-transplantation. Biomaterials. 2015;54:158-167.

54. Saengruengrit $C$, Ritprajak $P$, Wanichwecharungruang $S$, et al. The combined magnetic field and iron oxide-PLGA composite particles: effective protein antigen delivery and immune stimulation in dendritic cells. J Colloid Interface Sci. 2018;520:101-111.

55. Umashankar A, Corenblum MJ, Ray S, et al. Effects of the iron oxide nanoparticle Molday ION Rhodamine B on the viability and regenerative function of neural stem cells: relevance to clinical translation. Int J Nanomedicine. 2016;11:1731-1748.

56. Hohnholt MC, Geppert M, Luther EM, et al. Handling of iron oxide and silver nanoparticles by astrocytes. Neurochem Res. 2013;38:227-239. doi:10.1007/s11064-012-0930-y

57. Singh AV, Vyas V, Montani $\mathrm{E}$, et al. Investigation of in vitro cytotoxicity of the redox state of ionic iron in neuroblastoma cells. J Neurosci Rural Pract. 2012;3:301-310. doi:10.4103/ 0976-3147.102611

58. Gemmati D, Zeri G, Orioli E, et al. Polymorphisms in the genes coding for iron binding and transporting proteins are associated with disability, severity, and early progression in multiple sclerosis. BMC Med Genet. 2012;13:70. doi:10.1186/1471-235013-70

59. Pongrac IM, Pavičić I, Milić M, et al. Oxidative stress response in neural stem cells exposed to different superparamagnetic iron oxide nanoparticles. Int J Nanomedicine. 2016;11:1701-1715.

60. He C, Jiang S, Yao H, et al. Endoplasmic reticulum stress mediates inflammatory response triggered by ultra-small superparamagnetic iron oxide nanoparticles in hepatocytes. Nanotoxicology. 2018;12:1198-1214. doi:10.1080/17435390.2018.1530388
61. Schins RP, McAlinden A, MacNee W, et al. Persistent depletion of I kappa B alpha and interleukin-8 expression in human pulmonary epithelial cells exposed to quartz particles. Toxicol Appl Pharmacol. 2000;167:107-117. doi:10.1006/taap.2000.8982

62. Albrecht C, Schins RP, Höhr D, et al. Inflammatory time course after quartz instillation: role of tumor necrosis factor-alpha and particle surface. Am J Respir Cell Mol Biol. 2004;31:292-301. doi:10.1165/rcmb.2003-0300OC

63. Siglienti I, Bendszus M, Kleinschnitz C, et al. Cytokine profile of iron-laden macrophages: implications for cellular magnetic resonance imaging. $J$ Neuroimmunol. 2006;173:166-173. doi:10.1016/j.jneuroim.2005.11.011

64. Chouly C, Pouliquen D, Lucet I, et al. Development of superparamagnetic nanoparticles for MRI: effect of particle size, charge and surface nature on biodistribution. J Microencapsul. 1996;13:245-255. doi:10.3109/02652049609026013

65. Verma A, Stellacci F. Effect of surface properties on nanoparticle-cell interactions. Small. 2010;6:12-21. doi:10.1002/ smll.200901158

66. Patil US, Adireddy S, Jaiswal A, et al. In vitro/in vivo toxicity evaluation and quantification of iron oxide nanoparticles. Int J Mol Sci. 2015;16:24417-24450. doi:10.3390/ijms161024417

67. Wu VM, Huynh E, Tang S, et al. Brain and bone cancer targeting by a ferrofluid composed of superparamagnetic iron-oxide/silica/ carbon nanoparticles (earthicles). Acta Biomaterialia. 2019;88:422-447. doi:10.1016/j.actbio.2019.01.064

68. Yang CY, Tai MF, Lin CP, et al. Mechanism of cellular uptake and impact of ferucarbotran on macrophage physiology. PLoS One. 2011;6:e25524. doi:10.1371/journal.pone.0025524

69. Sherwood J, Lovas K, Rich M, et al. Shape-dependent cellular behaviors and relaxivity of iron oxide-based T(1) MRI contrast agents. Nanoscale. 2016;8:17506-17515. doi:10.1039/ C6NR06158C

70. Metz S, Bonaterra G, Rudelius M, et al. Capacity of human monocytes to phagocytose approved iron oxide MR contrast agents in vitro. Eur Radiol. 2004;14:1851-1858. doi:10.1007/ s00330-004-2405-2

71. Schlorf T, Meincke M, Kossel E, et al. Biological properties of iron oxide nanoparticles for cellular and molecular magnetic resonance imaging. Int J Mol Sci. 2010;12:12-23. doi:10.3390/ ijms 12010012

72. Binder FP, Ernst B. E- and P-selectin: differences, similarities and implications for the design of P-selectin antagonists. Chimia. 2011;65:210-213. doi:10.2533/chimia.2011.210

73. Kaila N, Somers WS, Thomas BE, et al. Quinic acid derivatives as sialyl Lewis(x)-mimicking selectin inhibitors: design, synthesis, and crystal structure in complex with E-selectin. J Med Chem. 2005;48:4346-4357. doi:10.1021/jm0500491

74. Girard C, Dourlat J, Savarin A, et al. Sialyl Lewis(x) analogs based on a quinic acid scaffold as the fucose mimic. Bioorg Med Chem Lett. 2005;15:3224-3228. doi:10.1016/j.bmcl.2005.05.004

75. Narkhede AA, Sherwood JA, Antone A, et al. Role of surface chemistry in mediating the uptake of ultrasmall iron oxide nanoparticles by cancer cells. ACS Appl Mater Interfaces. 2019;11:17157-17166. doi:10.1021/acsami.9b00606

76. Lévy M, Lagarde F, Maraloiu VA, et al. Degradability of superparamagnetic nanoparticles in a model of intracellular environment: follow-up of magnetic, structural and chemical properties. Nanotechnology. 2010;21:395103. doi:10.1088/0957-4484/21/39/ 395103

77. Rojas JM, Sanz-Ortega L, Mulens-Arias V, et al. Superparamagnetic iron oxide nanoparticle uptake alters M2 macrophage phenotype, iron metabolism, migration and invasion. Nanomedicine. 2016;12:1127-1138. doi:10.1016/j. nano.2015.11.020 
78. Wang N, Zhao JY, Guan X, et al. Biological characteristics of adipose tissue-derived stem cells labeled with amine-surfacemodified superparamagnetic iron oxide nanoparticles. Cell Biol Int. 2015;39:899-909. doi:10.1002/cbin.10457

79. Chen J, Ning E, Wang Z, et al. Docetaxel loaded mPEG-PLA nanoparticles for sarcoma therapy: preparation, characterization, pharmacokinetics, and anti-tumor efficacy. Drug Deliv. 2021;28:1389-1396. doi:10.1080/10717544.2021.1945167

80. Anselmo AC, Mitragotri S. Cell-mediated delivery of nanoparticles: taking advantage of circulatory cells to target nanoparticles. J Control Release. 2014;190:531-541. doi:10.1016/j.jconrel.20 14.03 .050

81. Peralta ME, Jadhav SA, Magnacca G, et al. Synthesis and in vitro testing of thermoresponsive polymer-grafted core-shell magnetic mesoporous silica nanoparticles for efficient controlled and targeted drug delivery. J Colloid Interface Sci. 2019;544:198-205. doi:10.1016/j.jcis.2019.02.086

82. Davoodi P, Lee LY, Xu Q, et al. Drug delivery systems for programmed and on-demand release. Adv Drug Deliv Rev. 2018;132:104-138.

83. Smith DM, Simon JK, Baker JR. Applications of nanotechnology for immunology. Nat Rev Immunol. 2013;13:592-605.

84. Zhao S, Yu X, Qian Y, et al. Multifunctional magnetic iron oxide nanoparticles: an advanced platform for cancer theranostics. Theranostics. 2020;10:6278-6309. doi:10.7150/thno.42564

85. Huang DM, Hsiao JK, Chen YC, et al. The promotion of human mesenchymal stem cell proliferation by superparamagnetic iron oxide nanoparticles. Biomaterials. 2009;30:3645-3651. doi:10.1016/j.biomaterials.2009.03.032

86. Skotland T, Sontum PC, Oulie I. In vitro stability analyses as a model for metabolism of ferromagnetic particles (Clariscan), a contrast agent for magnetic resonance imaging. J Pharm Biomed Anal. 2002;28:323-329. doi:10.1016/S0731-7085(01) 00592-1

87. Arbab AS, Wilson LB, Ashari P, et al. A model of lysosomal metabolism of dextran coated superparamagnetic iron oxide (SPIO) nanoparticles: implications for cellular magnetic resonance imaging. NMR Biomed. 2005;18:383-389. doi:10.1002/ nbm. 970

88. Gu J, Xu H, Han Y, et al. The internalization pathway, metabolic fate and biological effect of superparamagnetic iron oxide nanoparticles in the macrophage-like RAW264.7 cell. Sci China Life Sci. 2011;54:793-805. doi:10.1007/s11427-011-4215-5

89. Kremen TJ, Bez M, Sheyn D, et al. In vivo imaging of exogenous progenitor cells in tendon regeneration via superparamagnetic iron oxide particles. Am J Sports Med. 2019;47:2737-2744. doi: $10.1177 / 0363546519861080$

90. Yuan M, Wang Y, Qin YX. Engineered nanomedicine for neuroregeneration: light emitting diode-mediated superparamagnetic iron oxide-gold core-shell nanoparticles functionalized by nerve growth factor. Nanomedicine. 2019;21:102052. doi:10.1016/j. nano.2019.102052

91. Mailänder V, Lorenz MR, Holzapfel V, et al. Carboxylated superparamagnetic iron oxide particles label cells intracellularly without transfection agents. Mol Imaging Biol. 2008;10:138-146. doi:10.1007/s11307-007-0130-3

92. Jin WN, Yang X, Li Z, et al. Non-invasive tracking of CD4+ $\mathrm{T}$ cells with a paramagnetic and fluorescent nanoparticle in brain ischemia. J Cereb Blood Flow Metab. 2016;36:1464-1476. doi:10.1177/0271678X15611137

93. Zhang H, Xiang J, Wang Y, et al. In vivo tracking of novel SPIOMolday ION rhodamine-B ${ }^{\text {TM}}$-labeled human bone marrowderived mesenchymal stem cells after lentivirus- mediated COX-2 silencing: a preliminary study. Curr Gene Ther. 2014;14:136-145.
94. Ma L, Li MW, Bai Y, et al. Biological characteristics of fluorescent superparamagnetic iron oxide labeled human dental pulp stem cells. Stem Cells Int. 2017;2017:4837503. doi:10.1155/2017/ 4837503

95. Pongrac IM, Dobrivojević M, Ahmed LB, et al. Improved biocompatibility and efficient labeling of neural stem cells with poly (L-lysine)-coated maghemite nanoparticles. Beilstein J Nanotechnol. 2016;7:926-936. doi:10.3762/bjnano.7.84

96. Shen WB, Plachez C, Chan A, et al. Human neural progenitor cells retain viability, phenotype, proliferation, and lineage differentiation when labeled with a novel iron oxide nanoparticle, Molday ION Rhodamine B. Int J Nanomedicine. 2013;8:4593.

97. Wang X, Wei F, Liu A, et al. Cancer stem cell labeling using poly (L-lysine)-modified iron oxide nanoparticles. Biomaterials. 2012;33:3719-3732. doi:10.1016/j.biomaterials.2012.01.058

98. Ren Z, Wang J, Zou C, et al. Labeling of cynomolgus monkey bone marrow-derived mesenchymal stem cells for cell tracking by multimodality imaging. Sci China Life Sci. 2011;54:981-987. doi:10.1007/s11427-011-4239-X

99. Chang YK, Liu YP, Ho JH, et al. Amine-surface-modified superparamagnetic iron oxide nanoparticles interfere with differentiation of human mesenchymal stem cells. J Orthop Res. 2012;30:1499-1506. doi:10.1002/jor.22088

100. Magnitsky S, Walton RM, Wolfe JH, et al. Magnetic resonance imaging detects differences in migration between primary and immortalized neural stem cells. Acad Radiol. 2008;15:1269-1281. doi:10.1016/j.acra.2008.05.003

101. Tang H, Sha H, Sun H, et al. Tracking induced pluripotent stem cells-derived neural stem cells in the central nervous system of rats and monkeys. Cell Reprogram. 2013;15:435-442. doi:10.1089/cell.2012.0081

102. Eamegdool SS, Weible MW, Pham BT, et al. Ultrasmall superparamagnetic iron oxide nanoparticle prelabelling of human neural precursor cells. Biomaterials. 2014;35:5549-5564. doi:10.1016/j.biomaterials.2014.03.061

103. Wen X, Wang Y, Zhang F, et al. In vivo monitoring of neural stem cells after transplantation in acute cerebral infarction with dual-modal MR imaging and optical imaging. Biomaterials. 2014;35:4627-4635. doi:10.1016/j.biomaterials.2014.02.042

104. Gordon T. The physiology of neural injury and regeneration: the role of neurotrophic factors. J Commun Disord. 2010;43 (4):265-273. doi:10.1016/j.jcomdis.2010.04.003

105. Pilz D, Stoodley N, Golden JA. Neuronal migration, cerebral cortical development, and cerebral cortical anomalies. J Neuropathol Exp Neurol. 2002;61:1-11. doi:10.1093/jnen/ 61.1 .1

106. Andreas K, Georgieva R, Ladwig M, et al. Highly efficient magnetic stem cell labeling with citrate-coated superparamagnetic iron oxide nanoparticles for MRI tracking. Biomaterials. 2012;33:4515-4525. doi:10.1016/j.biomateri als.2012.02.064

107. Kurniawan DW, Booijink R, Pater L, et al. Fibroblast growth factor 2 conjugated superparamagnetic iron oxide nanoparticles (FGF2-SPIONs) ameliorate hepatic stellate cells activation in vitro and acute liver injury in vivo. $J$ Control Release. 2020;328:640-652. doi:10.1016/j.jconrel.2020.09.041

108. Mardhian DF, Storm G, Bansal R, et al. Nano-targeted relaxin impairs fibrosis and tumor growth in pancreatic cancer and improves the efficacy of gemcitabine in vivo. $J$ Control Release. 2018;290:1-10. doi:10.1016/j.jconrel.2018.09.031

109. Mulens-Arias V, Rojas JM, Sanz-Ortega L, et al. Polyethylenimine-coated superparamagnetic iron oxide nanoparticles impair in vitro and in vivo angiogenesis. Nanomedicine. 2019;21:102063. doi:10.1016/j.nano.2019.102063 
110. Soenen SJ, Himmelreich U, Nuytten N, et al. Cytotoxic effects of iron oxide nanoparticles and implications for safety in cell labelling. Biomaterials. 2011;32:195-205. doi:10.1016/j. biomaterials.2010.08.075

111. Zanotelli MR, Goldblatt ZE, Miller JP, et al. Regulation of ATP utilization during metastatic cell migration by collagen architecture. Mol Biol Cell. 2018;29:1-9. doi:10.1091/mbc.E1701-0041
112. Mahmoudi M, Shokrgozar MA, Simchi A, et al. Multiphysics flow modeling and in vitro toxicity of iron oxide nanoparticles coated with poly(vinyl alcohol). $J$ Phys Chem $C$. 2009;113:2322-2331. doi:10.1021/jp809453v

113. Jasmin GT, Louzada RA, Rosado-de-castro PH, et al. Tracking stem cells with superparamagnetic iron oxide nanoparticles: perspectives and considerations. Int $J$ Nanomedicine. 2017;12:779-793. doi:10.2147/IJN.S126530

\section{Publish your work in this journal}

The International Journal of Nanomedicine is an international, peerreviewed journal focusing on the application of nanotechnology in diagnostics, therapeutics, and drug delivery systems throughout the biomedical field. This journal is indexed on PubMed Central, MedLine, CAS, SciSearch ${ }^{\mathbb{B}}$, Current Contents ${ }^{\mathbb{B}} /$ Clinical Medicine, $^{2}$
Journal Citation Reports/Science Edition, EMBase, Scopus and the Elsevier Bibliographic databases. The manuscript management system is completely online and includes a very quick and fair peer-review system, which is all easy to use. Visit http://www.dovepress.com/ testimonials.php to read real quotes from published authors. 